\title{
Nota Científica \\ Primeiro registro de Tetranychus urticae (Acari: Tetranychidae) em mudas de teca no Brasil
}

\author{
Alexandre dos Santos ${ }^{1}$, Vagner Aniceto Teixeira1 ${ }^{1}$, Otávio Peres Filho², Milson Evaldo Serafin¹, Marçal Pedro Neto ${ }^{3}$, Carlos Alberto \\ da Cunha Oliveira ${ }^{1}$ \\ ${ }^{1}$ Instituto Federal de Educação, Ciência e Tecnologia de Mato Grosso, Av. dos Ramires, s/n, CEP 78200-000, Cáceres, Mato Grosso, Brasil \\ ${ }^{2}$ Universidade Federal do Mato Grosso, Departamento de Engenharia Florestal, Av. Fernando Corrêa da Costa, 2367, CEP 78125-070, Cuiabá, MT, Brasil \\ ${ }^{3}$ Universidade Federal do Tocantins,s CP 66, CEP 77402-970, Gurupi, TO, Brasil
}

\author{
"Autor correspondente: \\ alexandre.santos@cas.ifmt.edu.br \\ Termos para indexação: \\ Acaro fitófago \\ Proteção florestal \\ Viveiros \\ Index terms: \\ Mite phytophagous \\ Forest protection \\ Nursery \\ Histórico do artigo: \\ Recebido em 23/10/2013 \\ Aprovado em 09/05/2014 \\ Publicado em 07/07/2014
}

\begin{abstract}
Resumo - O ácaro fitófago Tetranychus urticae (Kock, 1836) (Acari: Tetranychidae) foi relatado e suas injúrias caracterizadas pela primeira vez em viveiro de produção mudas de teca (Tectona grandis) no Brasil.
\end{abstract}

\section{First report of Tetranychus urticae (Kock, 1836) (Acari: Tetranychidae) in teak seedlings (Tectona grandis) in Brazil}

\begin{abstract}
The mite Tetranychus urticae (Kock, 1836) (Acari: Tetranychidae) has been reported and the injuries characterized for the first time in nursery of teak (Tectona grandis) in Brazil.
\end{abstract}

doi: 10.4336/2014.pfb.34.78.603

A espécie Tectona grandis L. f. (Lamiaceae) de origem asiática, vulgarmente conhecida como teca, possui uma madeira com alto valor comercial e é apta a múltiplas aplicações tecnológicas (Ângelo et al., 2009). A teca destaca-se por sua resistência a agentes bióticos e rápido crescimento, além de ser uma madeira com alta remuneração no mercado internacional. Os plantios de teca são relativamente resistentes à infestação por pragas e doenças, apesar da homogeneidade genética dos clones. Destaca-se a espécie introduzida Hyblaea puera (Cramer, 1777) (Lepidoptera: Hyblaeidae) (lagarta-da-teca), sendo o principal inseto praga desta cultura, responsável por ocasionar perdas de até $44,1 \%$ no incremento em volume de plantios na Índia (Nair \& Mohandas, 1996). Porém, a relação entre a lagarta-da- teca e as perdas ocasionadas no Brasil é desconhecida. Outras espécies de insetos pragas são amplamente descritas para teca no Brasil (Peres Filho et al., 2006).

A importância dos ácaros em viveiros de espécies florestais advem principalmente da redução no desenvolvimento vegetativo das mudas em seu estágio inicial, porém a maiorias das espécies conhecidas de ácaros e suas injúrias foram relatadas em mudas de eucalipto (Flechtmann, 1993; Pereira et al., 2005), sendo inexistentes relatos de ácaros (Arachnida) em teca no Brasil.

Objetiva-se nesse trabalho descrever a ocorrência de ácaros fitófagos da espécie Tetranychus urticae (Kock, 1836) (Acari: Tetranychidae) e a caracterização das injúrias provocadas em mudas comerciais clonais de teca em viveiro. 
Durante o mês de maio de 2013 foi encontrada alta infestação por ácaros sobre as folhas de mudas de teca no viveiro floretal do Instituto Federal de Ciência e Tecnologia de Mato Grosso (IFMT), Campus Cáceres, (57\%40'51' O; 16¹1'42' S e altitude de 117 $\mathrm{m})$, Estado de Mato Grosso. Os ácaros foram coletados das plantas com um pincel e acondicionados em alcool $70 \%$. Posteriormente, foram enviados ao Laboratório de Fitossanidade do IFMT - Campus Cáceres, onde foram triados com auxílio de um microscópio esteroscópico (40x), fotografados e identificados. Concomitantemente, foram fotografadas as injúrias causadas às mudas e avaliada a porcentagem de desfolha (\%).

O ácaro foi identificado como T. urticae (Figura 1A). As injúrias observadas foram o bronzeamento e necrose das folhas (Figura 1B), com posterior queda das folhas atacadas. A desfolha média provida às plantas foi de $80,8 \% \pm 0,40 \%$, restando em alguns indivíduos apenas o broto apical, o que resultou em atraso no desenvolvimento vegetativo das plantas.

$\mathrm{O}$ ácaro T. urticae, comumente conhecido como ácaro-rajado, possui dimorfismo sexual, sendo as fêmeas ovaladas e os machos com a extremidade posterior do idiossoma mais estreita, com aproximadamente $300 \mu \mathrm{m}$ de comprimento. De modo geral, as fêmeas apresentam duas manchas verde-escuras no dorso, uma de cada lado, e realizam a postura de ovos esféricos de tonalidade amarelada entre os fios de teia que o ácaro tece na face abaxial das folhas (Gallo et al., 2002; Moraes \& Flechtmann, 2008).
A espécie T. urticae é considerada de grande importância econômica em inúmeros cultivos agrícolas (Lourenção et al., 2000; Maruyama et al., 2002; Esteves Filho et al., 2010), infestando as plantas durante todo o ano, com maior severidade nos períodos de baixa precipitação pluviométrica e temperaturas elevadas (Moro et al., 2012). Este gênero de ácaro foi relato em plantios de teca na América tropical (Arguedas-Gamboa, 2007; Camino \& Morales, 2013), e suas injúrias advém da perda da capacidade fotossintética das folhas atacadas, necrose nos tecidos foliares e queda prematura de folhas (Moraes \& Flechtmann, 2008).

O controle químico é o método mais empregado para o controle de ácaros (Andrei, 1999). No entanto, atualmente são inexistentes registros de acaricidas para T. grandis junto ao Ministério da Agricultura, Pecuária e Abastecimento (MAPA). Estudos têm enfatizado o emprego do controle biológico com o uso de ácaros predadores, principalmente aqueles pertencentes da família Phytoseidae, como Amblyseius californicus (McGregor, 1954) e Typhlodromalus tenuiscutus McMurtry \& Moraes, 1989 (Sá et al., 2002); e com o fungo entomopatogênico do gênero Neozygites sp. (Entomophthorales) (Delalibera Júnior et al., 2004).

Uma hipótese para explicar a ocorrência de T. urticae em mudas de teca é a presença de cultivos agrícolas em áreas adjacentes ao viveiro de produção de mudas. Porém, é necessário o desenvolvimento de estudos de dinâmica populacional, etiologia, biologia e identificação de inimigos naturais desses ácaros, que permitam a elaboração de um manejo de controle mais adequado.
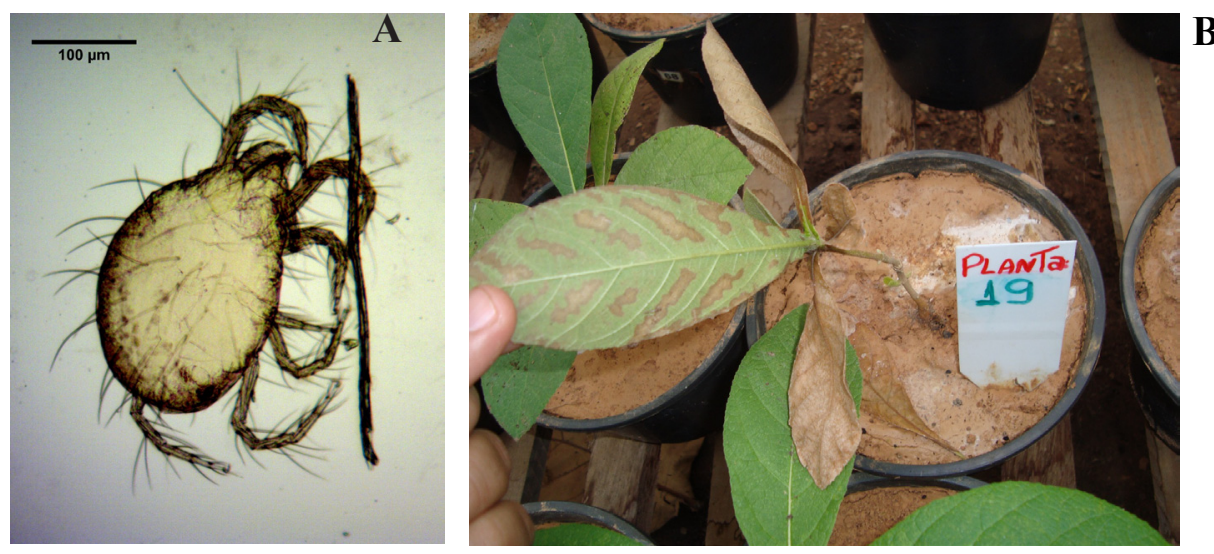

Figura 1. (A) Ácaro fitófago Tetranychus urticae (Kock, 1836) (Acari: Tetranychidae) e (B) Necrose foliar em mudas de Tectona grandis provocada pelo ácaro Tetranychus urticae em tecidos foliares de mudas de Tectona grandis. 


\section{Conclusão}

É reportado pela primeira vez no Brasil o ácaro Tetranychus urticae (Acari: Tetranychidae) em mudas de teca (Tectona grandis), sendo as injúrias promovidas pelo ácaro caracterizadas por necrose nos tecidos foliares e queda prematura de folhas. O ácaro demonstrou ter potencial para causar danos econômicos a viveiros de produção com essa espécie florestal.

\section{Agradecimentos}

Ao Conselho Nacional de Desenvolvimento Científico e Tecnológico (CNPq), Coordenação de Aperfeiçoamento de Pessoal de Nível Superior (CAPES) e Fundação de Amparo à Pesquisa do Estado de Mato Grosso (FAPEMAT).

\section{Referências}

ANDREI, E. Compêndio de defensivos agrícolas: guia prático de produtos fitossanitários para uso agrícola. 6. ed. São Paulo: Organização Andrei, 1999. 672 p.

ÂNGELO, H.; SILVA, V. S. M.; SOUZA, A. N.; GATTO, A. C. Aspectos financeiros da produção de teca no estado de Mato Grosso. Revista Floresta, Curitiba, v. 39, n. 1, p. 23-32, 2009.

ARGUEDAS-GAMBOA, M. Plagas y enfermedades forestales en Costa Rica. Revista Forestal Mesoamericana Kurú, San José, v. 4, n. 11-12, nesp. 69 p. 2007.

CAMINO, R.; MORALES, J. P. Las plantaciones de teca en América Latina: mitos y realidades. Turrialba: CATIE, 2013. 392 p.

DELALIBERA JUNIOR, I.; HAJEK, A. E.; HUMBER, R. A. Neozygites tanajoae sp. nov., a pathogen of the cassava green mite. Mycologia, New York, v. 96, n. 5, p. 1002-1009, 2004.

ESTEVES FILHO, A. B.; OLIVEIRA, J. V.; TORRES, J. B.; GONDIM JR.; M. G. C. Biologia comparada e comportamento de Tetranychus urticae Koch (Acari: Tetranychidae) e Phytoseiulus macropilis (Banks) (Acari: Phytoseiidae) em Algodoeiro Bollgard e Isolinha não transgênica. Neotropical Entomology, Londrina, v. 39, n. 3, p. 338-344, 2010.
FLECHTMANN, C. A. H. Dois ácaros novos para o eucalipto, com uma lista daqueles já assinalados para esta planta. IPEF, Piracicaba, n. 23, p. 43-46, 1983.

GALLO, D.; NAKANO, O.; SILVEIRA NETO, S.; CARVALHO, R. P. L.; BATISTA, G. C.; BERTI FILHO, E.; PARRA, J. R. P.; ZUCCHI, R. A.; ALVES, S. B.; VENDRAMIN, J. D.; MARCHINI, L. C.; LOPES, J. R. S.; OMOTO, C. Entomologia agrícola. Piracicaba: FEALQ, 2002. 920 p.

LOURENÇÃO, A. L.; MORAES, G. J.; PASSOS, F. A.; AMBrosAnO, G. M. B.; SILVA, L. V. F. Resistência de morangueiros a Tetranychus urticae Koch (Acari: Tetranychidae). Anais da Sociedade Entomológica do Brasil, Jaboticabal, v. 29, n. 2, p. 339-346, 2000.

MARUYAMA, W. I.; TOSCANO, L. C.; BOIÇA JÚNIOR, A. L.; BARBOSA, J. C. Resistência de genótipos de tomateiro ao ácaro rajado. Horticultura Brasileira, Brasília, DF, v. 20, n. 3, p. 480484, 2002.

MORAES, G. J.; FLECHTMANN, C. H. W. Manual de acarologia: acarologia básica e ácaros de plantas cultivadas no Brasil. Ribeirão Preto: Holos, 2008. 308 p.

MORO, L. B.; POLANCZYK, R. A.; CARVALHO, J. R.; PRATISSOLI, D.; FRANCO, C. R. Parâmetros biológicos e tabela de vida de Tetranychus urticae (Acari: Tetranychidae) em cultivares de mamão. Ciência Rural, Santa Maria, RS, n. 42, v. 3, p. 487-493, 2012.

NAIR, K. S. S.; MOHANDAS, K. Early events in the outbreak of the teak caterpillar, Hyblaea puera. International Journal of Ecology and Environmental Sciences, Jaipur, v. 22, p. 271-279, 1996.

PEREIRA, F. F.; ANJOS, N.; ALMADO, R. P.; RODRIGUES, L. A. L. Primeiro registro de Oligonychus yothersi (McGregor) (Acari: Tetranychidae) em Eucalyptus grandis Hill ex Maiden no Brasil. Revista Árvore, Viçosa, MG, v. 29. n. 4, p. 657-659, 2005.

PERES FILHO, O.; DORVAL, A.; BERTI FILHO, E. A entomofauna associada à teca, Tectona grandis L.f. (Verbenaceae) no Estado de Mato Grosso. Piracicaba: Elbergráfica, 2006. v. 1. 58 p.

SÁ, L. A. N.; NARDO, E. A. B.; TAMBASCO, F. J. Quarentena de agentes de controle biológico. In: PARRA, J. R. P.; BOTELHO, P. S. M.; CORRÊA-FERREIRA, B. S.; BENTO, J. M. S. (Ed.). Controle biológico no Brasil: parasitóide e predadores. São Paulo: Manole, 2002. p. 43-70. 
